\title{
Article \\ Effect of Mineral-Balanced Deep-Sea Water on Kidney Function and Renal Oxidative Stress Markers in Rats Fed a High-Salt Diet
}

\author{
So Min Jo ${ }^{1}$, Jain Nam ${ }^{1}$, Soo-yeon Park ${ }^{2}{ }^{\mathbb{D}}$, Geonhee Park ${ }^{3}$, Byeong Goo Kim ${ }^{3}$, Gwi-Hwa Jeong ${ }^{3}$, \\ Byung Serk Hurh ${ }^{3}$ and Ji Yeon Kim ${ }^{1,2, * \mathbb{D}}$
}

1 Department of Food Science and Technology, Seoul National University of Science and Technology, Seoul 01811, Korea; mindar71@naver.com (S.M.J.); jain3513@naver.com (J.N.)

2 Department of Nano Bio Engineering, Seoul National University of Science and Technology, Seoul 01811, Korea; sooyeon.park@seoultech.ac.kr

3 Sempio Fermentation Research Center, 183, Osongsaengmyeong 4-ro, Osong-eup, Heungdeok-gu, Cheongju-si 28156, Chungcheongbuk-do, Korea; pgeonhee@sempio.com (G.P.); kbyeonggoo@sempio.com (B.G.K.); jgwihwa@sempio.com (G.-H.J.); hbyungserk@sempio.com (B.S.H.)

* Correspondence: jiyeonk@seoultech.ac.kr; Tel.: +82-2-970-6740; Fax: +82-2-976-6460

check for updates

Citation: Jo, S.M.; Nam, J.; Park, S.-y.; Park, G.; Kim, B.G.; Jeong, G.-H.;

Hurh, B.S.; Kim, J.Y. Effect of

Mineral-Balanced Deep-Sea Water on

Kidney Function and Renal Oxidative Stress Markers in Rats Fed a

High-Salt Diet. Int. J. Mol. Sci. 2021,

22, 13415. https://doi.org/

10.3390/ijms222413415

Academic Editor: Fabrizio Damiano

Received: 18 October 2021

Accepted: 9 December 2021

Published: 14 December 2021

Publisher's Note: MDPI stays neutral with regard to jurisdictional claims in published maps and institutional affiliations.

Copyright: (c) 2021 by the authors. Licensee MDPI, Basel, Switzerland. This article is an open access article distributed under the terms and conditions of the Creative Commons Attribution (CC BY) license (https:// creativecommons.org/licenses/by/ $4.0 /)$

\begin{abstract}
This study investigated the effect of mineral-balanced deep-sea water (DSW) on kidney health using an animal model of kidney injury due to a high-sodium diet. High magnesium/low sodium (HMLS) and high magnesium/high calcium (HMHC) DSW samples with different mineral contents were prepared. Sprague-Dawley rats were fed an $8 \%$ sodium chloride $(\mathrm{NaCl})$ diet for four weeks to induce kidney injury, and each group was supplied with purified water or mineral water. Kidney injury was observed in the $\mathrm{NaCl}$ group according to increased kidney injury markers and malondialdehydes, providing evidence of oxidative stress. However, the kidney injury was repaired by the intake of mineral-balanced DSW. It was confirmed that the HMLS and HMHC groups showed improved $\mathrm{Na}^{+}$excretion through the urine. Kidney injury markers in urine decreased and upregulation of low-density lipoprotein receptor-related protein 2 mRNA expression was observed in the HMLS and HMHC groups. In addition, superoxide dismutase activity was increased in the HMHC groups. The gene expression patterns of the RNA sequencing were similar between the CON and HMLS groups. These results suggest that DSW has beneficial effects on kidney health due to the balanced magnesium and calcium levels in models of kidney injury caused by excessive sodium intake.
\end{abstract}

Keywords: deep sea water; kidney; high-salt diet; antioxidant; kidney injury; sodium excretion; magnesium; calcium; RNA-seq

\section{Introduction}

At present, people are consuming more salt in their diets. The general sodium intake of adults in the United States continues to exceed the chronic disease risk reduction (CDRR) intake guidelines established by considering the association between sodium intake and the risk of high blood pressure [1]. The adverse effects of a high-salt diet have been demonstrated in many studies. A high salt intake increases blood pressure, leading to hypertension and possibly even heart failure [2]. In addition, it has been reported that high salt intake levels increase the possibility of metabolic syndromes such as obesity and type 2 diabetes [3].

The kidneys play a crucial role in maintaining our health. They regulate the homeostasis of minerals such as calcium (Ca), magnesium $(\mathrm{Mg})$, phosphorus $(\mathrm{P})$, and sodium (Na) through filtration and reabsorption processes [4,5]. Fellner et al. [6] have shown that high-salt diet blunts renal blood flow (RBF) and glomerular filtration rate (GFR). There have been many studies of the relationship between a high salt intake and kidney injury, 
confirming that a high-salt diet causes renal tubular injury, renal fibrosis, and deteriorates the pathophysiological renal function [7,8]. Kidney injuries, when not treated, can progress to kidney failure and can have catastrophic effects such as cardiovascular disease [9]. In sum, kidney injuries associated with a high salt diet can affect kidney function, such as filtration and reabsorption processes. In addition, impaired kidney function is associated with reactive oxygen species (ROS). In rats, a high-salt diet increases ROS production and induces dysfunction of mitochondria in the kidneys [10], and decreased GFR via NADPH oxidase-derived ROS generation [11].

Minerals are essential for biological processes in organisms and help to keep the body functioning properly. They play a vital role in animal metabolism by participating as an enzyme cofactor, contributing to proper cellular and tissue function, and even improving the immune system [12,13]. It has been discovered that the supplementation of magnesium can help to decrease oxidative stress and recover antioxidant levels by synthesizing glutathione and vitamin C [14]. Deep sea water (DSW) is known to have numerous beneficial effects on health, as it contains various minerals, such as $\mathrm{Ca}, \mathrm{Mg}$, selenium (Se), and zinc (Zn) [15]. Accordingly, there have been many attempts to process this water as drinking water. Research on the beneficial effects on health of DSW is ongoing.

Previously, we confirmed the effects of mineral-balanced DSW on human embryonic kidney (HEK293) cells exposed to sodium chloride $(\mathrm{NaCl})$ [16]. This line of research was continued in a study involving an animal model fed a high-salt diet using two DSW samples found to be most effective in reducing oxidative stress in HEK293 cells. Meanwhile, many studies have investigated kidney damage due to high salt levels, but there are few studies, to the best of our knowledge, about how mineral-balanced DSW affects the kidneys in a high-salt model. Experiments were performed to determine whether DSW could protect kidney function by promoting sodium excretion or ameliorating oxidative stress. In addition, we checked whether both mineral-balanced DSW with different magnesium and calcium contents can help protect kidney function.

Sprague-Dawley rats were fed an $8 \% \mathrm{NaCl}$ diet for four weeks to induce kidney injury, and each group was given purified water or mineral-balanced water as drinking water. After four weeks, clinical parameters and biomarkers were measured to confirm the effects of DSW on kidney injury. This study also provided an analysis of RNA levels with regard to the effects of DSW on high-salt-induced kidney injury.

\section{Results}

\subsection{Clinical Symptoms}

Data pertaining to the clinical symptoms are shown in Table 1. No weight loss or increase of more than $5 \%$ was observed in the $\mathrm{NaCl}$ group and the sample groups compared to the $\mathrm{CON}$ group. A decrease in food intake was observed at the first day of experiment due to the replacement of $8 \% \mathrm{NaCl}$ feed in the $\mathrm{NaCl}, \mathrm{HMLS}$, and HMHC groups. Then, the food intake gradually increased, and no significant differences in food intake between all groups were observed in the 4 th week. On day 28 of the test period, a $131 \%$ increase in the water intake of the $\mathrm{NaCl}$ group was noted compared to the $\mathrm{CON}$ group, while the water intake levels of the HMLS and HMHC groups increased by $31.3 \%$ and $23.0 \%$, respectively, compared to the $\mathrm{NaCl}$ group. Kidney weight was increased in the $\mathrm{NaCl}$, HMLS and HMHC groups compared to the CON group. There was no significant difference between the $\mathrm{NaCl}$, HMLS and HMHC groups. 
Table 1. Body Weight, Food Intake, Water Intake, Kidney Weight and Blood Pressure Values of Rats.

\begin{tabular}{|c|c|c|c|c|}
\hline & \multicolumn{4}{|c|}{ Group } \\
\hline & $\mathrm{CON}(\mathrm{n}=8)$ & $\mathrm{NaCl}(\mathrm{n}=8)$ & HMLS $(n=8)$ & HMHC $(n=8)$ \\
\hline \multicolumn{5}{|l|}{ Body Weight (g) } \\
\hline Initial Weight & $267.3 \pm 5.9$ & $268.4 \pm 11.0$ & $268.8 \pm 10.6$ & $267.6 \pm 11.9$ \\
\hline Final Weight & $406.9 \pm 15.1$ & $393.0 \pm 13.2$ & $393.5 \pm 13.2$ & $395.5 \pm 18.2$ \\
\hline $\begin{array}{l}\text { Food Intake } \\
\text { (g/day) }\end{array}$ & $25.6 \pm 0.8$ & $26.1 \pm 0.6$ & $26.1 \pm 0.1$ & $26.2 \pm 0.5$ \\
\hline $\begin{array}{l}\text { Water Intake } \\
\text { (mL/day) }\end{array}$ & $49.0 \pm 2.1^{c}$ & $113.5 \pm 2.1^{b}$ & $149.0 \pm 8.6^{\mathrm{a}}$ & $139.6 \pm 23.9^{\mathrm{a}}$ \\
\hline $\begin{array}{l}\text { Kidney Weight } \\
\text { (2ea) (g) }\end{array}$ & $2.62 \pm 0.26^{b}$ & $3.07 \pm 0.31^{\mathrm{a}}$ & $3.09 \pm 0.16^{\mathrm{a}}$ & $3.03 \pm 0.16^{\mathrm{a}}$ \\
\hline $\begin{array}{l}\text { Blood Pressure } \\
\quad(\mathrm{mmHg})\end{array}$ & $113.1 \pm 4.6^{b}$ & $161.8 \pm 6.0^{a}$ & $161.1 \pm 6.3^{a}$ & $160.7 \pm 3.7^{\mathrm{a}}$ \\
\hline
\end{tabular}

CON, normal diet + distilled water; $\mathrm{NaCl}, 8 \% \mathrm{NaCl}$ diet + distilled water; $\mathrm{HMLS}, 8 \% \mathrm{NaCl}$ diet + high magnesium low sodium water; $\mathrm{HMHC}, 8 \% \mathrm{NaCl}$ diet + high magnesium high calcium water. Different letters above the data indicate significant differences (Duncan's multiple range test; $p<0.05$ ).

The systolic blood pressure of the CON group was $106.9 \pm 8.4 \mathrm{mmHg} \sim 113.1 \pm 4.6 \mathrm{mmHg}$ on average during the experimental period and remained below the normal value of $120 \mathrm{mmHg}$. In the $\mathrm{NaCl}$ group, it increased by $30.1 \%$ compared to the $\mathrm{CON}$ group and the HMLS and HMHC groups showed no significant differences compared to the $\mathrm{NaCl}$ group.

\subsection{Urine Volume, Sodium Excretion, and Urine Protein}

Figure 1 shows the influence of mineral water on the kidneys through the urine volume, urine protein levels, and sodium excretion in the urine. The urine volume increased until the third week in all groups but dropped at the fourth week for the $\mathrm{NaCl}$ group. During the fourth week, the urine volume of the $\mathrm{NaCl}$ group decreased by $63.44 \%$ compared to that of the CON group. In the HMLS and HMHC groups, the urine volume increased by $90.36 \%$ and $96.39 \%$, respectively, compared to the $\mathrm{NaCl}$ group (Figure $1 \mathrm{~A}$ ). It was confirmed that the intake of HMLS and HMHC decreased the reduction of the urine volume initially created by a high-salt diet.

The amount of urinary protein was increased by $216.88 \%$ in the $\mathrm{NaCl}$ group compared to that in the CON group. In the mineral water groups, urinary protein excretion was reduced by $34.94 \%$ in the HMLS group and $33.06 \%$ in the HMHC group compared to the $\mathrm{NaCl}$ group (Figure 1B). This result suggests that mineral water reduced urine protein excretion stemming from a high-salt diet.

The concentration of sodium in the urine is shown in Figure 1C. Figure 1D presents values obtained by correcting the amount of sodium excretion according to the urine volume. Sodium excretion in the $\mathrm{NaCl}$ group was decreased $17.18 \%$ compared to the $\mathrm{CON}$ group. However, compared to the $\mathrm{NaCl}$ group, sodium excretion increased significantly by $61.08 \%$ in the HMLS group and $34.03 \%$ in the HMHC group. It was shown that mineral water increased sodium excretion through urine.

\subsection{Kidney Injury Markers}

The effect of mineral water on kidney function was confirmed by analyzing acute kidney injury markers, in this case, neutrophil gelatinase-associated lipocalin (NGAL), albumin, and creatinine in the urine. In the $\mathrm{NaCl}$ group, NGAL increased by $252.43 \%$ over the control group. The level of NGAL showed significant decreases, $24.28 \%$ in the HMLS group and $39.08 \%$ in the HMHC group compared to the $\mathrm{NaCl}$ group (Figure $2 \mathrm{~A}$ ). $\mathrm{NaCl}$ group showed increased levels of urinary albumin and creatinine compared to the CON group. Albumin in the HMLS group declined by $72.94 \%$, and it declined by $43.09 \%$ in the $\mathrm{HMHC}$ group, a significant level compared to the $\mathrm{NaCl}$ group (Figure 2B). Mineral water slightly reduced urine creatinine levels by $12.22 \%$ in the HMLS and $20.14 \%$ in the HMHC groups (Figure 2C). 
(A)

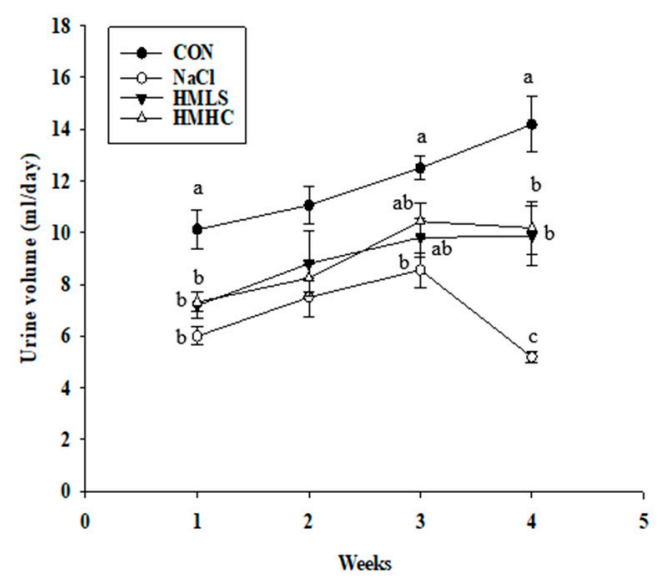

(C)

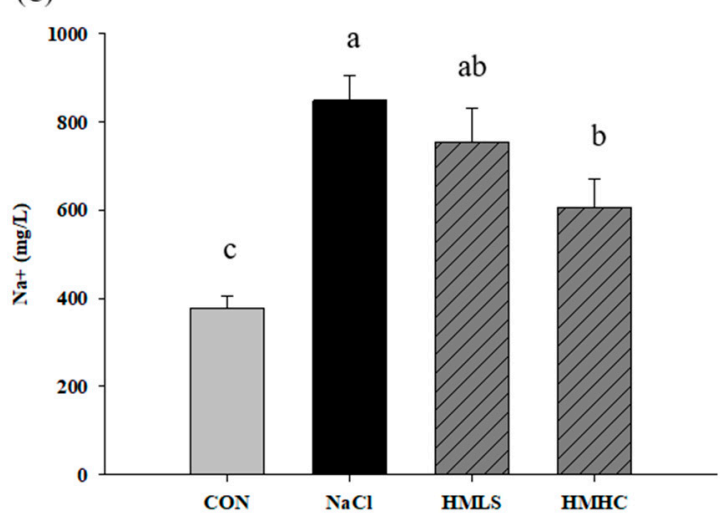

(B)

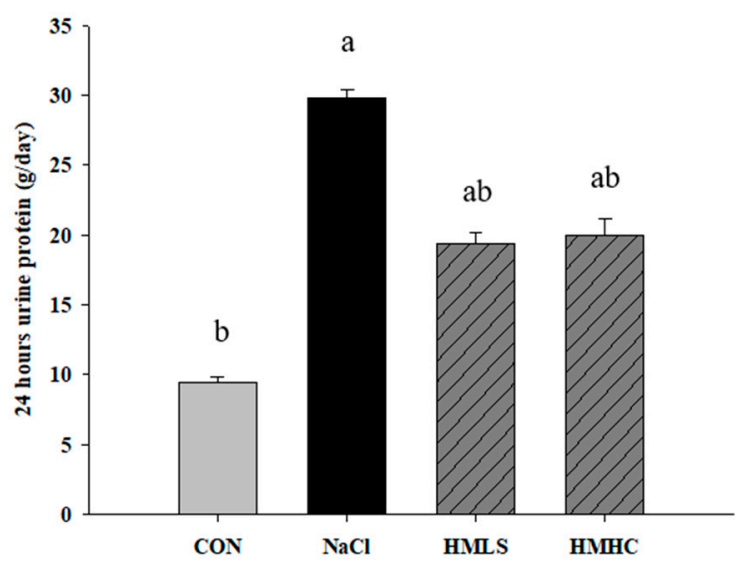

(D)

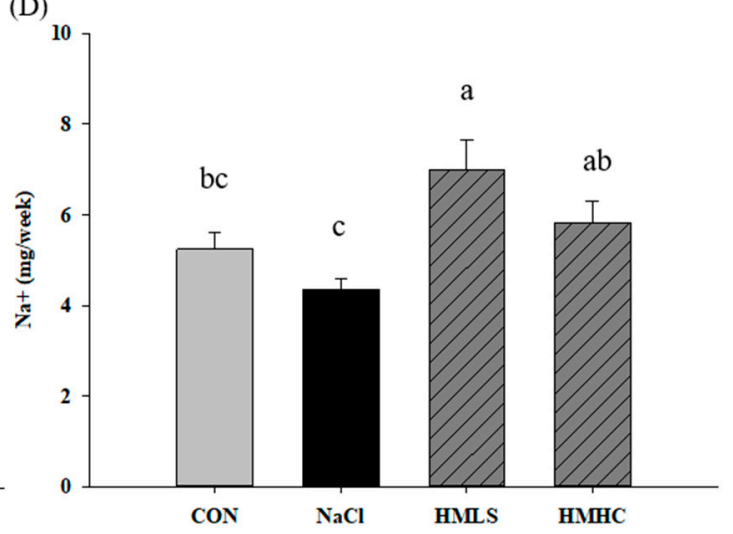

Figure 1. Effect of mineral-balanced DSW on the kidneys through a urine analysis: (A) urine volume at four weeks, (B) urine protein during the fourth week, (C) sodium excretion in the urine during the fourth week, and (D) sodium excretion in the urine in the fourth week corrected according to the urine volume. $\mathrm{CON}$, normal diet + distilled water; $\mathrm{NaCl}, 8 \% \mathrm{NaCl}$ diet + distilled water; HMLS, 8\% NaCl diet + high magnesium low sodium water; $\mathrm{HMHC}, 8 \% \mathrm{NaCl}$ diet + high magnesium high calcium water. Bonferroni test was applied to urine volume. Other data were evaluated using Duncan's multiple range test. Different letters above the bars indicate significant differences $(p<0.05)$.

(A)

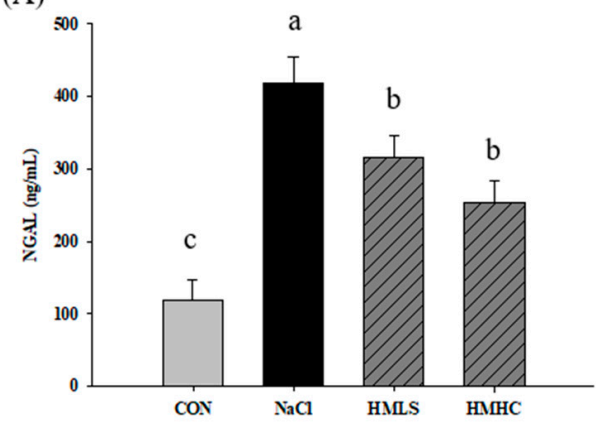

(B)

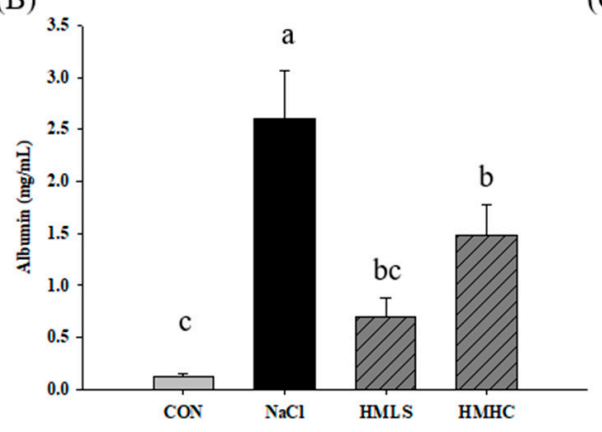

(C)

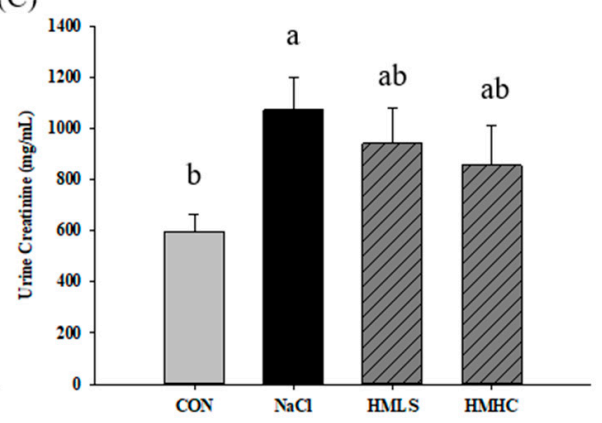

Figure 2. Effects of mineral-balanced DSW on kidney injury markers measured in urine: (A) NGAL, (B) albumin, and (C) creatinine. $\mathrm{CON}$, normal diet + distilled water; $\mathrm{NaCl}, 8 \% \mathrm{NaCl}$ diet + distilled water; $\mathrm{HMLS}, 8 \% \mathrm{NaCl}$ diet + high magnesium low sodium water; $\mathrm{HMHC}, 8 \% \mathrm{NaCl}$ diet + high magnesium high calcium water. Different letters above the bars indicate significant differences (Duncan's multiple range test; $p<0.05$ ). 


\subsection{Relative mRNA Expression of Genes Related to Kidney Function}

LRP2 mRNA expression was significantly decreased due to $\mathrm{NaCl}$ intake. However, the consumption of HMLS significantly increased the LRP2 mRNA expression level, and there were no significant differences in the HMHC group (Figure 3).

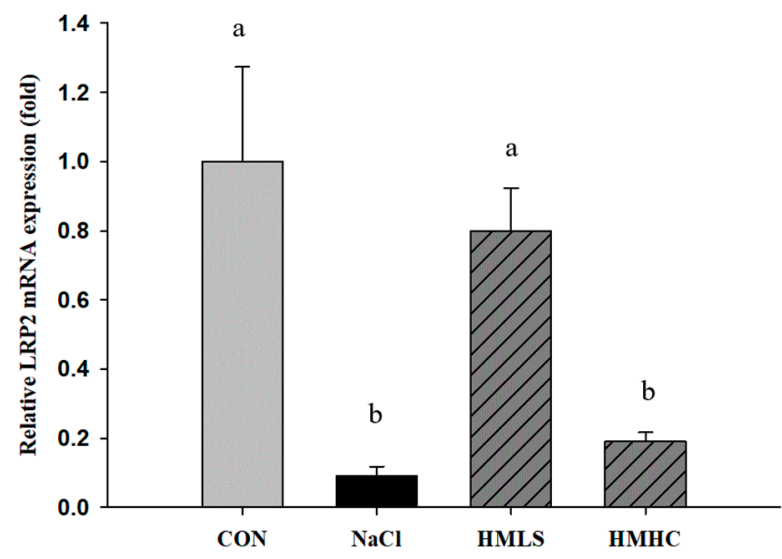

Figure 3. Effects of mineral-balanced DSW on low-density lipoprotein-related protein 2 (LRP2) expression levels: $\mathrm{CON}$, normal diet + distilled water; $\mathrm{NaCl}, 8 \% \mathrm{NaCl}$ diet + distilled water; HMLS, $8 \% \mathrm{NaCl}$ diet + high magnesium low sodium water; $\mathrm{HMHC}, 8 \% \mathrm{NaCl}$ diet + high magnesium high calcium water. Different letters above the bars indicate significant differences (Duncan's multiple range test; $p<0.05)$.

\subsection{Oxidative Stress and Antioxidant Activity}

Figure 4 shows the effect of mineral water on oxidative stress and antioxidant activity in kidney tissue. Oxidative stress can be confirmed by MDA level. The MDA value was increased by $32.65 \%$ in the $\mathrm{NaCl}$ group compared to that in the CON group. However, it was also found that mineral water significantly reduced MDA levels. Compared to the $\mathrm{NaCl}$ group, the level of MDA was decreased by $23.80 \%$ in the HMLS group and by $41.00 \%$ in the HMHC group (Figure 4A).

(A)

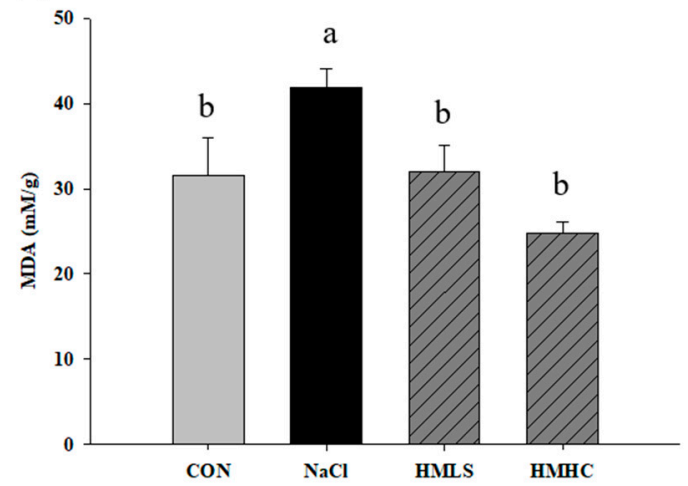

(B)

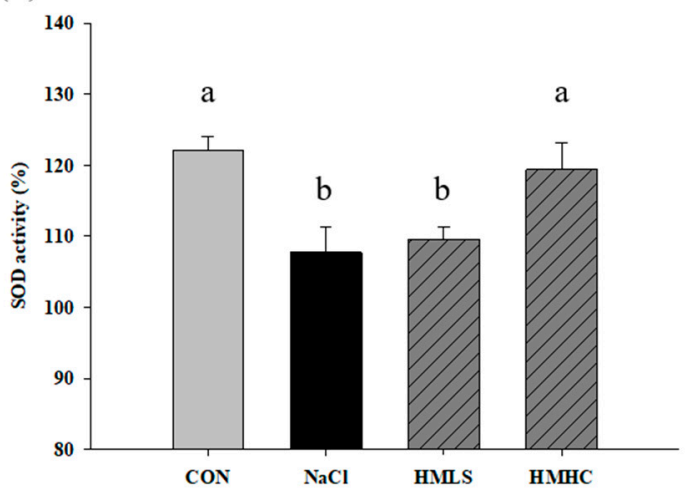

Figure 4. Effects of mineral-balanced DSW on antioxidant effect in kidney tissue: (A) malondialdehyde, and (B) SOD activity (\%). $\mathrm{CON}$, normal diet + distilled water; $\mathrm{NaCl}, 8 \% \mathrm{NaCl}$ diet + distilled water; HMLS, $8 \% \mathrm{NaCl}$ diet + high magnesium low sodium water; $\mathrm{HMHC}, 8 \% \mathrm{NaCl}$ diet + high magnesium high calcium water. Different letters above the bars indicate significant differences (Duncan's multiple range test; $p<0.05$ ).

SOD activity was $122.02 \%$ in the CON group and was decreased by $11.70 \%$ in the $\mathrm{NaCl}$ group compared to the $\mathrm{CON}$ group. For the HMHC group, it increased significantly by $10.81 \%$ compared to the $\mathrm{NaCl}$ group. However, there was no significant difference in the HMLS group (Figure 4B). 


\subsection{Relative mRNA Expression of Antioxidant Genes}

To confirm the exact pathway of the antioxidant effect of mineral-balanced DSW water, the mRNA expression levels of the antioxidant-related genes were examined (Figure 5). Compared to the $\mathrm{CON}$ group, superoxide dismutase 1 (SOD1), glutathione peroxidase (GPx), and glutathione disulfide reductase (GSR) mRNA expression levels were significantly decreased in the $\mathrm{NaCl}$ group. However, SOD1 and GSR mRNA expression levels showed increasing tendency in the HMLS group compared to the $\mathrm{NaCl}$ group, whereas there were no differences in the HMHC group. Regarding the GPx mRNA expression outcomes, they showed slight increases, albeit not at significant levels, in both the HMLS and HMHC groups. On the other hand, heme oxygenase-1 (HO-1) mRNA expression level was significantly increased in the $\mathrm{NaCl}$ group compared to that in the $\mathrm{CON}$ group. The corresponding values were significantly decreased in the HMLS and HMHC groups. This tendency was in agreement with the differentially expressed genes (DEG) result from RNA sequencing.

(A)

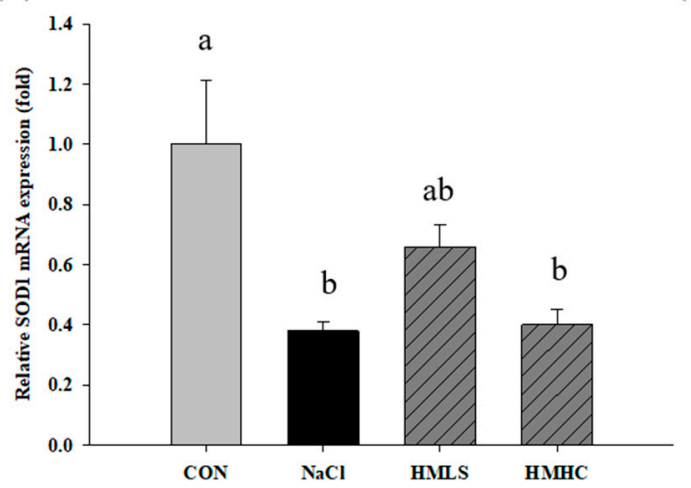

(C)

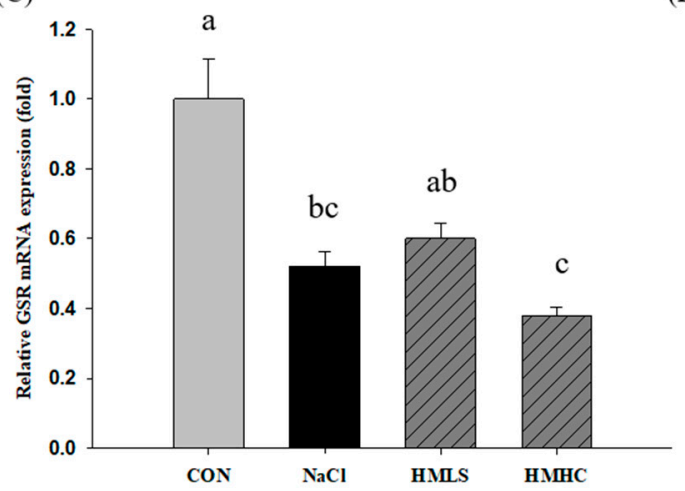

(B)

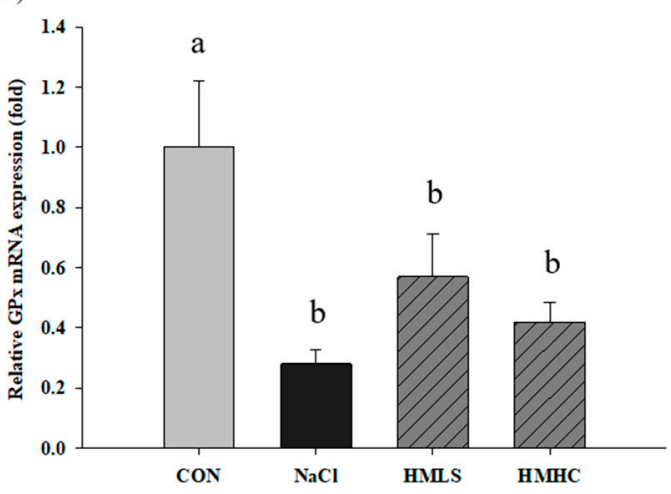

(D)

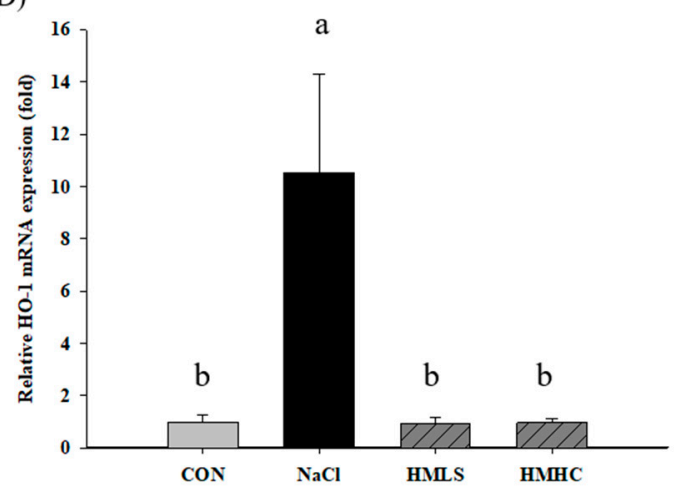

Figure 5. Effects of mineral-balanced DSW on antioxidant related mRNA expression levels of (A) superoxide dismutase 1 (SOD1), (B) glutathione peroxidase (GPx), (C) glutathione disulfide reductase (GSR), and (D) heme oxygenase-1 (HO-1). $\mathrm{CON}$, normal diet + distilled water; $\mathrm{NaCl}, 8 \% \mathrm{NaCl}$ diet + distilled water; HMLS, $8 \% \mathrm{NaCl}$ diet + high magnesium low sodium water; $\mathrm{HMHC}, 8 \% \mathrm{NaCl}$ diet + high magnesium high calcium water. Different letters above the bars indicate significant differences (Duncan's multiple range test; $p<0.05$ ).

\subsection{Total RNA-Sequencing and Differentially Expressed Gene Analysis}

Differentially expressed genes (DEGs) were analyzed using the ExDEGA tool provided by EBiogen. In this case, 17,048 genes were screened from the kidneys of rats, of which the fold change $\geq 2$, normalized data $(\log 2)=0$, and $p$-values $\leq 0.05$ were selected for CON vs. $\mathrm{NaCl}, \mathrm{HMLS}$ vs. $\mathrm{NaCl}$, and $\mathrm{HMHC}$ vs. $\mathrm{NaCl}$. The total number of DEGs in CON vs. $\mathrm{NaCl}$ was 326, of which 233 were up-regulated and 93 were down-regulated. The total number of DEGs in HMLS vs. $\mathrm{NaCl}$ was 471, of which 56 were up-regulated and 415 were down-regulated. The total number of DEGs in HMHC vs. $\mathrm{NaCl}$ was 231 , of which 89 were 
up-regulated and 142 were down-regulated. In the three comparison groups, 41 genes had a common difference in their expression values. The 41 genes whose expression values were significantly different in all three comparison groups are listed in Figure 6.

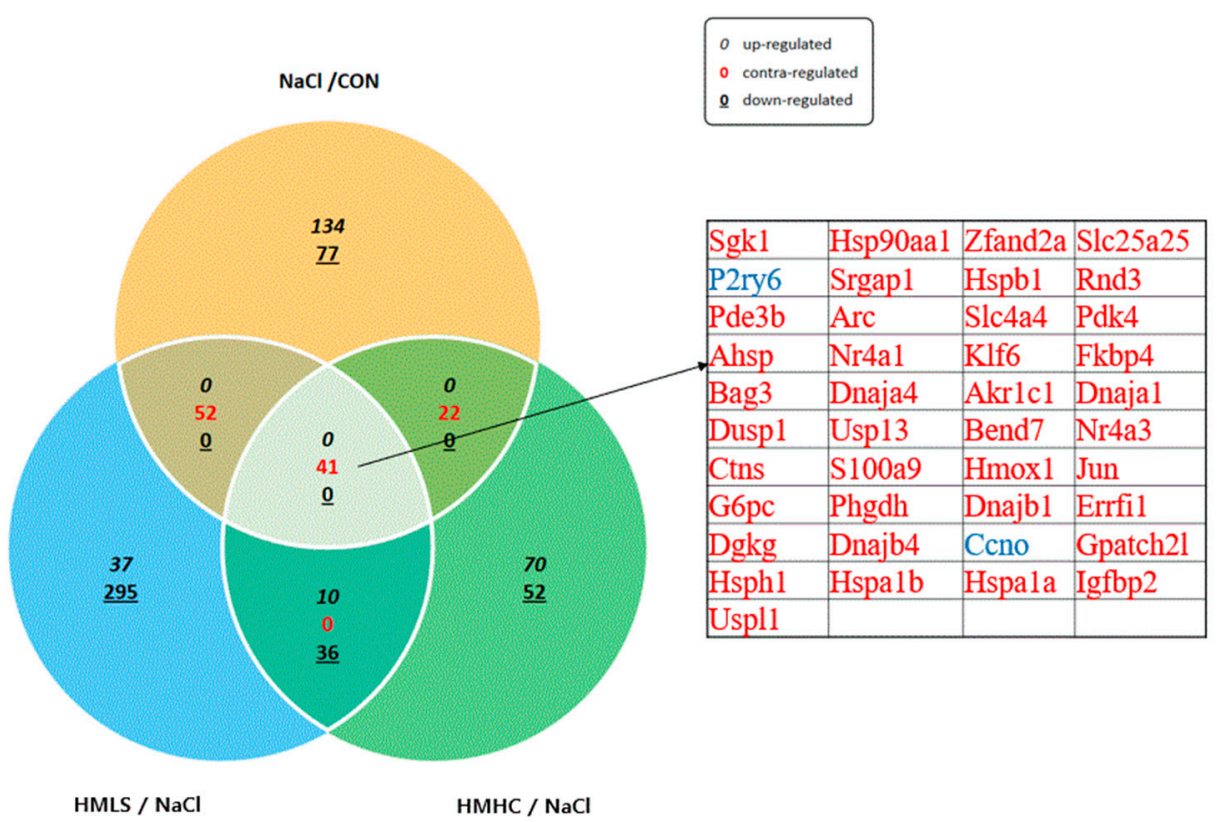

Figure 6. Examination of differentially expressed genes in kidney tissues. CON, normal diet + distilled water; $\mathrm{NaCl}, 8 \% \mathrm{NaCl}$ diet + distilled water; $\mathrm{HMLS}, 8 \% \mathrm{NaCl}$ diet + high magnesium low sodium water; $\mathrm{HMHC}, 8 \% \mathrm{NaCl}$ diet + high magnesium high calcium water. Differentially expressed genes screened from the kidneys of rats. Genes that satisfied the criteria of fold change $\geq 2$, normalized data $(\log 2)=0$, and $p$-value $\leq 0.05$ were selected for CON vs. $\mathrm{NaCl}, \mathrm{HMLS}$ vs. $\mathrm{NaCl}$, and $\mathrm{HMHC}$ vs. $\mathrm{NaCl}$.

The expression patterns between the groups were confirmed as an image through scatter plots (Figure 7A-C). The genes above the red diagonal line are those whose fold change increased by two-fold or more, and the genes below the green line are those for which the fold change decreased by two-fold or more.

From the 17,048 genes in total, 424 genes were selected corresponding to the "response to oxidative stress (GO:0006979)," and 344 genes corresponding to the category related to renal function, such as "renal system development (GO:0072001)" and "renal sodium excretion (GO:0035812)" were also selected by means of Gene Ontology and Go annotation (https:/ / www.ebi.ac.uk/QuickGO (accessed on 6 December 2021)).

A hierarchical clustering heatmap was drawn using the $\mathrm{MeV}$ program to determine the degree of expression similarity between the samples (Figure 7D,E). The length of the hierarchical branch indicates the degree of expression similarity between the groups: the shorter this distance is, the more similar the levels are. Regarding the heatmap related to the renal function category, the expression patterns were similar between the $\mathrm{NaCl}$ and HMHC groups, and the HMLS group showed the expression pattern most similar to that of the CON group. Here, 15 genes were expressed differently in $\mathrm{NaCl} v$ s. HMLS, with hemoglobin subunit beta $(\mathrm{Hbb})$ and nephrosis 2 idiopathic steroid-resistant (Nphs2) also down-regulated to 0.238 and 0.240 -fold, respectively (Table 2). In the heatmap of the "response to oxidative stress" category, the $\mathrm{NaCl}$ and $\mathrm{HMHC}$ groups showed similar expression patterns, with the CON group showing the expression pattern most similar to that of the HMLS group. There were 13 genes whose expression levels were significantly changed in $\mathrm{NaCl}$ vs. HMLS. Above them, heme oxygenase-1 (HO-1) was the most downregulated gene, with a fold change of 0.062 (Table 3 ). 
(A)

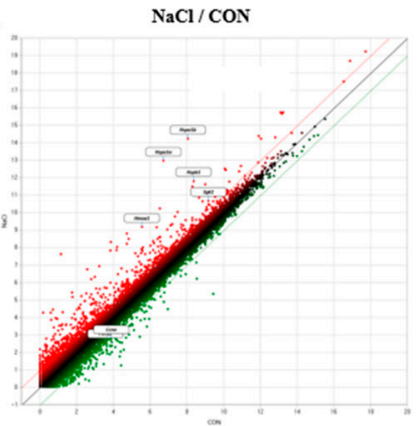

(B)

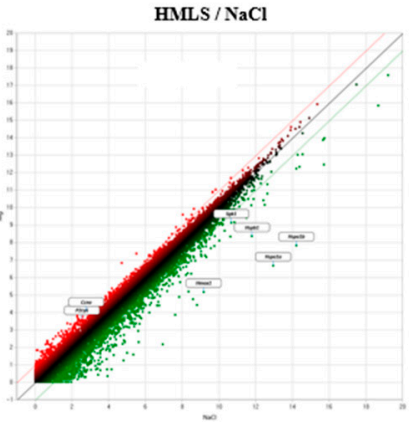

(C)

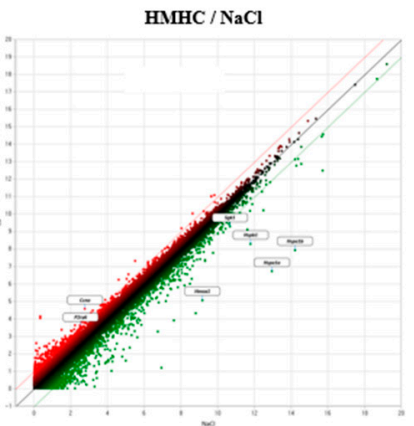

(D)

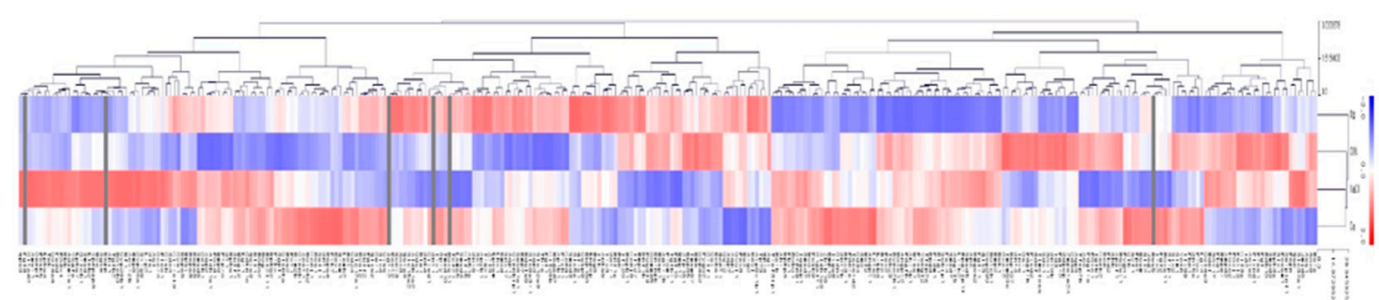

(E)

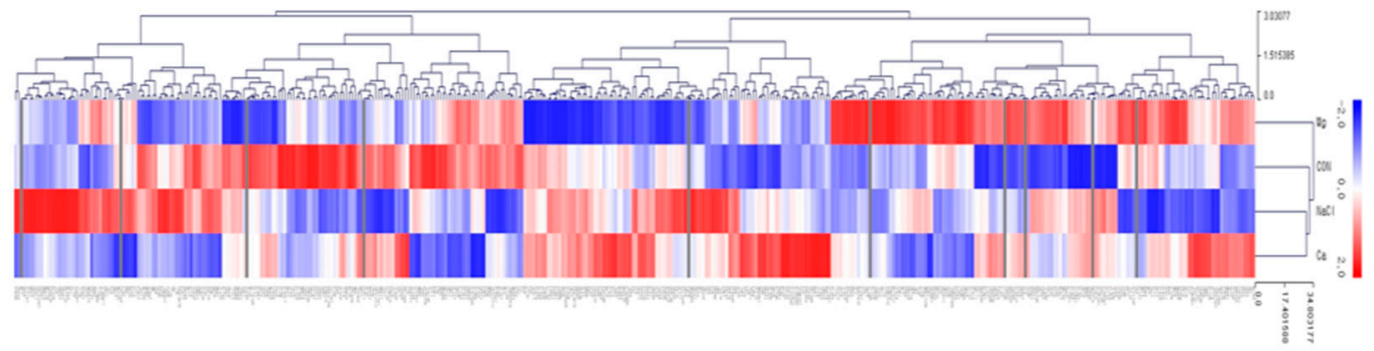

Figure 7. Differentially expressed genes in kidney tissues: (A-C) Scatter plots showing the correlation between the mRNA expression level in CON vs. $\mathrm{NaCl}, \mathrm{HMLS}$ vs. NaCl, and $\mathrm{HMHC}$ vs. $\mathrm{NaCl}$. (D) Heatmap hierarchical clustering with 344 differentially expressed genes related to renal function. (E) Heatmap hierarchical clustering with 424 differentially expressed genes related to the response to oxidative stress. $\mathrm{CON}$, normal diet + distilled water; $\mathrm{NaCl}, 8 \% \mathrm{NaCl}$ diet + distilled water; HMLS, $8 \% \mathrm{NaCl}$ diet + high magnesium low sodium water; $\mathrm{HMHC}, 8 \% \mathrm{NaCl}$ diet + high magnesium high calcium water.

Table 2. Renal-System-Related Gene Expressions in the $\mathrm{NaCl}$ vs. HMLS Group.

\begin{tabular}{ccc}
\hline Gene ID & Gene Name & Fold Change \\
\hline Down-regulated & & 0.238 \\
Hbb & Hemoglobin Subunit beta & 0.240 \\
Nphs2 & T-box18 & 0.282 \\
Tbx18 & nephrosis 2, idiopathic, steroid-resistant & 0.292 \\
Col4a3 & collagen type IV alpha 3 chain, transcript variant X1 & 0.340 \\
Myocd & myocardin, transcript variant X2 & 0.377 \\
Apc & APC, WNT signaling pathway regulator, transcript variant X1 & 0.386 \\
Col4a4 & collagen type IV alpha 4 chain & 0.392 \\
Adamts1 & ADAM metallopeptidase with thrombospondin type 1 motif, 1 & 0.401 \\
Tsc1 & tuberous sclerosis 1, transcript variant X1 & 0.457 \\
Fat4 & FAT atypical cadherin 4, transcript variant X1 & 0.477 \\
Ctnnd1 & catenin delta 1, transcript variant X6 & 0.480 \\
Ahi1 & Abelson helper integration site 1 & 0.484 \\
Lrrk2 & leucine-rich repeat kinase 2, transcript variant X1 & 0.487 \\
Hoxc11 & homeobox C11 & 0.498 \\
Vegfa & vascular endothelial growth factor A, transcript variant 1 \\
\hline
\end{tabular}


Table 3. Response to Oxidative-Stress-Related Gene Expression in the $\mathrm{NaCl}$ vs. HMLS Group.

\begin{tabular}{ccc}
\hline Gene ID & Gene Name & Fold Change \\
\hline Down-regulated & Heme Oxygenase 1 & 0.062 \\
Hmox1 & Heat Shock Protein Family B (Small) Member 1 & 0.092 \\
Hspb1 & Nuclear Receptor Subfamily 4 Group A Member 3 & 0.099 \\
Nr4a3 & Jun Proto-Oncogene, AP-1 Transcription Factor Subunit & 0.142 \\
Jun & Hemoglobin Subunit beta & 0.238 \\
Hbb & Kruppel Like Factor 6 & 0.323 \\
Klf6 & Aryl Hydrocarbon Receptor Nuclear Translocator-like, transcript & 0.375 \\
Arntl & variant X4 & \\
& Uveal Autoantigen with Coiled-coil domains and Ankyrin repeats, & 0.400 \\
Uaca & transcript variant X1 & 0.407 \\
ll1r1 & Interleukin 1 Receptor type 1, transcript variant X8 & 0.438 \\
Dusp1 & Dual Specificity Phosphatase 1 & 0.440 \\
Egfr & Epidermal Growth Factor Receptor & 0.467 \\
Abcc2 & ATP binding cassette subfamily C member 2 & 0.484 \\
Lrrk2 & Leucine-rich repeat kinase 2, transcript variant X1 & \\
\hline
\end{tabular}

\subsection{GO and KEGG Enrichment Analyses of DEG}

In the $\mathrm{NaCl}$ vs. HMLS results, 471 genes whose expression values were changed were analyzed by means of a DAVID analysis to determine their function and pathway. In the GO cellular component, they were grouped as follows: "Hemoglobin complex", "Perinuclear region of cytoplasm" and "Extracellular exosome". They were also grouped into categories entitled "Negative regulation of inclusion body assembly", "Oxygen transport" and "Negative regulation of neuron apoptotic process" with respect to the GO biological process. An additional grouping was "Unfolded protein binding", "Chaperone binding" and "Oxygen transporter activity". In the KEGG pathway, they were grouped according to the "MAPK signaling pathway", "African trypanosomiasis" and the "Estrogen signaling pathway". These results demonstrated that there were many genes related to oxygen transport (Table 4).

Table 4. DAVID Functional Analysis and KEGG pathway Results of DEGs in the HMLS vs. NaCl Group.

\begin{tabular}{|c|c|c|c|c|}
\hline Category & Term & ID & $p$ Value & Benjamini \\
\hline \multirow[t]{3}{*}{ GO, cellular component } & Hemoglobin complex & GO:0005833 & $4.4 \times 10^{-5}$ & $3.4 \times 10^{-3}$ \\
\hline & Perinuclear region of cytoplasm & GO:0048471 & $4.5 \times 10^{-5}$ & $3.4 \times 10^{-3}$ \\
\hline & Extracellular exosome & GO:0070062 & $3.6 \times 10^{-4}$ & $1.8 \times 10^{-2}$ \\
\hline \multirow[t]{3}{*}{ GO, biological process } & $\begin{array}{l}\text { Negative regulation of inclusion } \\
\text { body assembly }\end{array}$ & GO:0090084 & $1.1 \times 10^{-5}$ & $8.0 \times 10^{-3}$ \\
\hline & Oxygen transport & GO:0015671 & $7.4 \times 10^{-5}$ & $2.2 \times 10^{-2}$ \\
\hline & $\begin{array}{l}\text { Negative regulation of neuron } \\
\text { apoptotic process }\end{array}$ & GO:0043524 & $9.0 \times 10^{-5}$ & $2.2 \times 10^{-2}$ \\
\hline \multirow[t]{3}{*}{ GO, molecular function } & Unfolded protein binding & GO:0051082 & $2.0 \times 10^{-6}$ & $4.8 \times 10^{-4}$ \\
\hline & Chaperone binding & GO:0051087 & $3.8 \times 10^{-5}$ & $4.7 \times 10^{-3}$ \\
\hline & Oxygen transporter activity & GO:0005344 & $8.9 \times 10^{-5}$ & $7.2 \times 10^{-3}$ \\
\hline \multirow[t]{3}{*}{ KEGG pathways } & MAPK signaling pathway & - & $4.1 \times 10^{-4}$ & $4.6 \times 10^{-2}$ \\
\hline & African trypanosomiasis & - & $1.1 \times 10^{-3}$ & $5.7 \times 10^{-2}$ \\
\hline & Estrogen signaling pathway & - & $1.7 \times 10^{-3}$ & $5.7 \times 10^{-2}$ \\
\hline
\end{tabular}

\section{Discussion}

Modern people who consume a high-salt diet are prone to various diseases, and the kidneys, which are important organs that play a role in the removal of waste from our bodies and in regulating water, salt, electrolytes, and maintaining the acid-base balance in our bodies, can also be affected by a high-salt diet, possibly leading to kidney injury. We confirmed that mineral-balanced DSW can effectively reduce kidney injury caused by 
alleviating oxidative stress and that it can help with the excretion of sodium in the kidneys through a model in which rats were fed a high-salt diet to induce kidney injury.

The renin-angiotensin-aldosterone system (RAAS) contributes to kidney injury [17] and is stimulated when the body receives excessive salt [18]. Angiotensinogen is cut by renin and forms angiotensin I (Ang I), after which it turns into angiotensin II (Ang II) by the actions of angiotensin-converting enzyme (ACE). Ang II is responsible for producing aldosterone, and aldosterone is known to induce injury to kidney tissues and is involved in podocyte injury, fibrotic processes, and renal inflammation $[17,19]$. ROS are produced in the kidney in response to aldosterone [19]. In the case of inappropriate sodium intake or balance, aldosterone can activate NADPH oxidase which is a source of ROS [20]. Therefore, a high-salt diet induces kidney injury by increasing oxidative stress [21].

Oxidative stress can cause proteinuria, which is an important factor in defining chronic kidney disease [22]. Conventional markers of kidney injury such as albumin and creatinine are widely used but sometimes show lower sensitivity levels. There are several novel markers of kidney injury, including vanin-1, kim-1 and NGAL, and it is known that NGAL increases more rapidly than urinary albumin $[7,23]$. In this study, we examined urinary albumin, creatinine, and NGAL as kidney injury markers and verified the effects of mineral water on kidney injury in terms of both conventional markers and novel markers.

Megalin, or low-density lipoprotein-related protein 2 (LRP2) is a transmembrane protein that functions as a receptor of multiple ligands [24]. In the kidney, megalin plays a central role by reabsorbing filtered molecules, including albumin and NGAL, at the proximal tubules $[23,25]$. When the kidney is damaged, megalin is harmed, and the mRNA expression of megalin can be down-regulated, resulting in proteinuria [26,27]. Washino [23] also reported that an $8 \% \mathrm{NaCl}$ diet can reduce the mRNA expression of megalin in WKY rats, suggesting that this megalin damage reduces the reabsorption of NGAL. In our study, the mRNA expression of LRP2 was decreased by $\mathrm{NaCl}$ intake but was rescued by the consumption of HMLS. This result implies that mineral-balanced DSW repaired harmed transmembrane protein receptors. In addition, this repair resulted in decreased levels of urinary proteins.

This study measured $\mathrm{Na}^{+}$excretion in the urine during the fourth week and corrected it according to the urine volume. We confirmed that $\mathrm{Na}^{+}$excretion was reduced by $\mathrm{NaCl}$, whereas DSW increased it. Other studies reported that supplementation of calcium and magnesium will increase sodium excretion through the urine [28,29]. From these results, it can be inferred that DSW can help to prevent kidney injury by reducing sodium remaining in the body by helping it be excreted through the urine.

It is known that continuous natriuresis to maintain sodium balance is accompanied by an increase in blood pressure [30]. The renal excretion capacity and blood pressure follow the following compensatory system. When arterial pressure rises above the normal range, the increased pressure increases the excretion of water and salt from the kidneys. As a result, blood volume decreases, followed by a decrease in blood pressure [30-32]. Rats in the $\mathrm{NaCl}$, HMLS and HMHC groups drank more water due to $\mathrm{NaCl}$ intake, and their blood pressure increased. In the HMLS and HMHC groups, sodium excretion through urine was achieved, but blood pressure was still increased. Therefore, the compensation system was not applied well. There are mechanisms to control blood pressure, such as the renin-angiotensin system, however, as shown in the discussion, there was no significant change observed in aldosterone level. HMLS and HMHC may help with immediate sodium excretion but appears to be insufficient to alter blood pressure control mechanisms.

A previous study showed that magnesium supplementation lowered oxidative stress in diabetic rats in relation to decreased MDA levels, revealed that $\mathrm{Mg}$ is associated with the restoration of antioxidant levels and decreased oxidative stress by way of directly removing free radicals [14]. On the other hand, NADPH oxidase acts as a major contributor of ROS generation $[33,34]$. Although NADPH oxidase-related experiments were not conducted in our study, it is expected that magnesium contained in mineral-balanced water may play a role in inhibiting NADPH oxidase according to the research results showing that 
magnesium inhibits NADPH oxidase enzymes [35]. Gao [36] reported that mineral-rich salt generates less oxidative stress than mineral-deficient salt in rats. According to our findings, MDA was decreased by HMLS and HMHC and SOD activity was increased by HMHC, suggesting that mineral-balanced DSW acts as an effective antioxidant. It is assumed that $\mathrm{Mg}$ in DSW reduces oxidative stress by repressing free radical production [37], scavenging free radicals directly [38], and increasing SOD activity [38,39]. Furthermore, it has been reported that a high-calcium diet increases SOD activity in the kidneys and protects the kidneys from injury by reducing oxidative stress [40]. We also sought to confirm that supplements of DSW regulate the mRNA expression of antioxidant-related genes. SOD1 converts superoxide anion into hydrogen peroxide and oxygen, and the hydrogen peroxide produced here is decomposed into water and oxygen through CAT [41]. GPx (glutathione peroxidase) converts reduced glutathione (GSH) to oxidized glutathione (GSSG) while removing hydrogen peroxide via $\mathrm{NADP}^{+}$, and GSR (glutathione reductase) acts in the opposite way to regenerate GSH, an antioxidant protein. It is an enzyme that aids in antioxidant activity [42,43]. However, we did not clarify why the SOD activity is not increased by HMLS.

Following RNA-seq, among the 13 genes involved in the "response to oxidative stress" between the $\mathrm{NaCl}$ and HMLS groups, Hmox1 was the most down-regulated gene in the HMLS group compared to the $\mathrm{NaCl}$ group. $\mathrm{HO}-1$ is induced in response to kidney injury and regulates oxidative stress [44]. We investigated DEGs with the opposite trend of an increase or decrease in $\mathrm{NaCl}$ compared to $\mathrm{CON}$, and in HMLS or HMHC compared to the $\mathrm{NaCl}$. In line with our findings, Zhang [45] reported that heat shock protein, heme oxygenase-1, and S100 calcium-binding proteins genes were upregulated during an ischemia-reperfusion injury in rat kidneys. Specifically, heat shock protein upregulation is assumed to be a physiological reaction to protect the kidney from cellular damage [45]. Nphs2 encodes a podocyte protein, podocin [46,47]. We assumed that the reason for the upregulation of $\mathrm{Nphs} 2$ in the $\mathrm{NaCl}$ group is to provide a protective response against podocyte injury due to high levels of salt.

In the DAVID analysis, we found that many genes were related to oxygen-carrying pathways, including the $\mathrm{Hbb}$ gene. $\mathrm{Hbb}$ mRNA expression is up-regulated by oxidative stress, and this can serve as an inhibitor of oxidative damage [48]. Our findings clearly demonstrate that oxidative stress was induced by a high-salt diet in the $\mathrm{NaCl}$ group and demonstrate an antioxidant effect of mineral-balanced DSW in the HMLS and HMHC groups. It is assumed that mineral-balanced DSW prevents the kidneys from being damaged by regulatory genes related to oxygen transport.

The positive effect of mineral water may be influenced not only by $\mathrm{Mg}$ and $\mathrm{Ca}$ but also by $\mathrm{Mg} / \mathrm{Ca}$ or $\mathrm{Na} / \mathrm{Ca}$ ratios. Many studies have investigated ideal ratios of minerals and the purported positive effect on health $[49,50]$. According to our study, we propose a ratio of 4.3 or 1.1 for $\mathrm{Mg} / \mathrm{Ca}$ as effective for health. However, further study is needed to discover a clear mechanism by which this proposed $\mathrm{Mg} / \mathrm{Ca}$ ratio work.

In this study, we examined the effects of mineral-balanced DSW on kidney health through high-salt diets fed to rats. This study provides various types of proof of the protective effect of mineral-balanced DSW on the kidneys. Specifically, we found that mineral-balanced DSW restores kidney injury through the excretion of $\mathrm{Na}^{+}$via the urine and a reduction of oxidative stress. This study also suggests an ideal ratio of mineralbalanced DSW. However, this study has several limitations. We examined GPx, GSR and LRP2 mRNA expressions but did not verify them at the protein level. The lack of western blotting or immunohistology data and inflammatory markers are limitations of this study. Although DSW was expected to reduce aldosterone and blood pressure levels by regulating how RAAS affects renal injury, no significant changes were detected (data not shown). Moreover, the effects of different $\mathrm{Mg}$ / Ca ratios on kidney health remain unclear. Finally, we emphasized the necessity for clinical studies of the effects of mineral-balanced DSW on alleviating kidney injury caused by a high-salt diet and on kidney health. 


\section{Materials and Methods}

\subsection{Preparation of Mineral-Balanced Deep Sea Water (DSW)}

DSW was obtained from the East Sea at a depth of $510 \mathrm{~m}$. DSW was desalted via reverse osmosis (RO) and electrodialysis (ED) process. DSW was processed with the 'mineral module manufacturing technology' of Sempio Fermentation R\&D Center (Cheongju, Korea), which can design target-customized mineral modules. Through this process, the DSW was manufactured into two types of samples: termed here the high magnesium low sodium (HMLS) and high magnesium high calcium (HMHC) samples. All DSW samples were provided by the Sempio Fermentation R\&D Center. The mineral contents of the DSW samples are shown in Table 5.

Table 5. Mineral contents of the water sample.

\begin{tabular}{|c|c|c|c|c|c|c|}
\hline \multirow{2}{*}{ Sample } & \multicolumn{4}{|c|}{ Mineral Contents (ppm) } & \multirow{2}{*}{$\mathrm{Na} / \mathrm{Mg}$} & \multirow{2}{*}{$\mathrm{Mg} / \mathrm{Ca}$} \\
\hline & $\mathrm{Na}^{+}$ & $\mathrm{Mg}^{2+}$ & $\mathrm{K}^{+}$ & $\mathrm{Ca}^{2+}$ & & \\
\hline DSW & 10700 & 1380 & 480 & 390 & 7.75 & 3.5 \\
\hline HMLS & 36 & 179 & 1.7 & 41.5 & 0.2 & 4.3 \\
\hline HMHC & 133 & 211 & 48 & 200 & 0.63 & 1.1 \\
\hline
\end{tabular}

DSW, deep sea water; HMLS, high magnesium low sodium; HMHC, high magnesium high calcium. $\mathrm{Na}^{+}, \mathrm{Mg}^{2+}$, $\mathrm{K}^{+}$and $\mathrm{Ca}^{2+}$ ions were measured in the DSW and water samples. The ratio of $\mathrm{Na} / \mathrm{Mg}$ and $\mathrm{Mg} / \mathrm{Ca}$ is shown in the table.

\subsection{Animals}

The study was approved by the Institutional Animal Care and Use Committee (No. WJIACUC20191007-4-01). Male Sprague-Dawley (SD) rats were purchased from Daehan Biolink (Eumseong, Korea). After seven days of acclimatization, the experiment was conducted from eight weeks of age. Two rats were housed together in a cage. All rats were randomly divided into four groups $(\mathrm{n}=8)$ consisting of control (normal diet and water), $\mathrm{NaCl}(8 \% \mathrm{NaCl}$ diet and water), HMLS ( $8 \% \mathrm{NaCl}$ diet + HMLS mineral water), HMHC $(8 \% \mathrm{NaCl}$ diet $+\mathrm{HMHC}$ mineral water) groups. Normal diet was sodium deficient diet TD.90228 (Harlan Inc., Indianapolis, IN, USA) and 8\% NaCl diet was TD.92012 (Harlan Inc., Indianapolis, IN, USA). The rats were given free access to food and water. During the experimental period, the body weights, food intake, and water intake levels were checked five times a week. Blood pressure was measured once a week with tail cuff methods using BP-2000 series II (Visitech systems, Inc., Apex, NC, USA). The rats were placed in metabolic cages for $12 \mathrm{~h}$ a week and urine samples were collected. When the experiment was completed, the rats were anesthetized using an isoflurane respiratory anesthetic method.

\subsection{Measurement of Urine Protein}

Protein concentrations in the urine samples were determined according to the manual of the Rat Urinary Protein Assay Kits used here (Chondrex, Woodinville, WA, USA). Urine samples were centrifuged at 10,000 rpm for three minutes. $3 \%$ sulfosalicylic acid was added to each sample and $0.1 \mathrm{~N} \mathrm{HCl}$ was added as a blank. The samples were incubated for ten minutes at room temperature and read using a plate reader at OD $450 \mathrm{~nm}$.

\subsection{Analysis of Trace Minerals in Urine}

$\mathrm{Na}^{+}$was measured in the urine during the fourth week using an inductively coupled plasma mass spectrometer (ICP-MS). Urine samples were analyzed after six-fold dilution.

\subsection{Measurement of Kidney Injury Markers in Urine}

Kidney injury markers were measured in the urine of the rats at four weeks. The levels of neutrophil gelatinase-associated lipocalin (NGAL), albumin, and creatinine were analyzed with an ELISA kit following the manufacturer's protocol. NGAL ELISA assay 
kits (Eagle Biosciences Inc., Amherst, NH, USA), Albumin (Chondrex, Woodinville, WA, USA), and creatinine kits (Abcam, Cambridge, UK) were used.

\subsection{Total RNA Extraction and Quantitative Reverse Transcription (qRT-PCR)}

Total RNA was extracted from the kidney tissues and homogenized with $1 \mathrm{~mL}$ of TRIzol (Life Technologies, Rockville, MD, USA) per $100 \mathrm{~g}$ of tissue. cDNA was synthesized using a Transcriptor first strand cDNA synthesis kit (Life Technologies, Rockville, MD, USA) following the manufacturer's protocol. qRT-PCR was performed. Relative mRNA expression levels were calculated using the comparative $2^{-\Delta \Delta \mathrm{Cq}}$ method and were normalized with GAPDH. The primers were as follows: GPx forward $5^{\prime}$-tccettgcaaccagttcg- $3^{\prime}$ and reverse $5^{\prime}$-cttgaggctgttcaggatctc- $3^{\prime}$; GSR forward $5^{\prime}$-ttcctcatgagaaccagatcc- $3^{\prime}$ and reverse $5^{\prime}$-ctgaaagaacccatcactggt- $3^{\prime}$; SOD1 forward $5^{\prime}$-ccagcggatgaagagagg- $3^{\prime}$ and reverse $5^{\prime}$ ggacacattggccacacc- $3^{\prime} ;$ HO-1 forward $5^{\prime}$-gtcaggtgtccagggaagg- $3^{\prime}$ and reverse $5^{\prime}$ ctcttccagggccgtataga-3'; LRP2 forward $5^{\prime}$-ctcccctggagctgatga- $3^{\prime}$ and reverse $5^{\prime}$ ttgggttttcgtttgaagatg-3'; Gapdh forward $5^{\prime}$-gcaagttcaacggcacagt- $3^{\prime}$ and reverse $5^{\prime}$ gaagatggtgatgggtttcc-3'.

\subsection{Measurement of Malondialdehyde (MDA)}

MDA levels in the kidney tissues were measured according to the method of Ohkawa [51]. Kidney tissues were washed with $0.9 \% \mathrm{NaCl}$ and homogenized in $0.9 \mathrm{~mL}$ of $1.15 \% \mathrm{KCl}$ per $100 \mathrm{mg}$ of tissue. $8.1 \%$ sodium dodecyl sulfate, $20 \%$ acetic acid and $0.9 \%$ thiobarbituric acid were mixed and added to a $10 \%$ tissue homogenate. Distilled water was added, and the mixture was incubated at $95^{\circ} \mathrm{C}$ for one hour. After adding n-butanol: pyridine (15:1, $v / v$ ) and distilled water, the mixture was centrifuged at $4{ }^{\circ} \mathrm{C}$ at $4000 \times g$ for $10 \mathrm{~min}$. The supernatant was moved to a 96-well plate and the absorbance levels were measured at $532 \mathrm{~nm}$.

\subsection{Measurement of Superoxide Dismutase (SOD) Activity}

The SOD activity of the kidney tissue was measured using an ELISA kit (Biovision, Milpitas, CA, USA). The kidney tissues were washed with DPBS and homogenized in ice-cold $0.1 \mathrm{M}$ Tris/ $\mathrm{HCl}$ at $\mathrm{pH} 7.4$ containing $0.5 \%$ Triton $\mathrm{X}-100,5 \mathrm{mM} \beta$-mercaptoethanol, and $0.1 \mathrm{mg} / \mathrm{mL}$ phenylmethylsulfonyl fluoride. The tissue homogenate was centrifuged at $14,000 \times g$ for five minutes at $4{ }^{\circ} \mathrm{C}$ and supernatant was used for the assay. The assay was performed according to the protocol provided in the kit.

\subsection{Statistical Analysis}

All data are expressed as the mean \pm standard error of the mean (SEM). Data were analyzed by means of a one-way analysis of variance (ANOVA) followed by Duncan's multiple range test in SAS 9.4 (SAS, Cary, NC, USA). $p$-values of $<0.05$ were considered as statistically significant. For multiple comparisons data, Bonferroni analysis were applied $(p<0.05)$.

\subsection{RNA-Sequencing}

Total RNA was isolated using TRIzol reagent (Invitrogen, Waltham, MA, USA) in the kidneys. RNA quantification was performed using an ND-2000 spectrophotometer (Thermo Inc., Waltham, MA, USA). Libraries were prepared from the total RNA using a NEBNext Ultra II Directional RNA-Seq Kit (New England BioLabs, Inc., Ipswich, MA, USA). The mRNA isolation step was performed using a Poly(A) RNA selection kit (LEXOGEN, Inc., Wien, Austria); this was followed by cDNA synthesis and shearing following the manufacturer's instructions. The enrichment step was carried out using PCR. Subsequently, libraries were checked using an Agilent 2100 bioanalyzer (DNA High Sensitivity Kit) to evaluate the mean fragment size. Quantification was performed using a library quantification kit with a StepOne Real-Time PCR system (Life Technologies, Inc., Carlsbad, CA, USA). High-throughput sequencing was performed as paired-end 100 sequencing 
using HiSeq X10 (Illumina, Inc., San Diego, CA, USA). Quality control of the raw sequencing data was carried out via FastQC. We removed adapter and low-quality reads $(<Q 20)$ using FASTX_Trimmer and BBMap. Gene expression levels were assumed using FPKM (fragments per $\mathrm{kb}$ per million reads) values by Cufflinks and were normalized based on the quantile normalization method using EdgeR within R. Graphic visualization was carried out using ExDEGA (E-Biogen, Inc., Seoul, Korea).

Author Contributions: Conceptualization, G.P., B.G.K., G.-H.J., B.S.H. and J.Y.K.; data curation, S.M.J.; formal analysis, S.M.J. and J.N.; investigation, S.M.J. and J.N.; methodology, J.Y.K.; project administration, J.Y.K.; resources, J.Y.K.; supervision, J.Y.K.; visualization, S.M.J. and S.-y.P.; writingoriginal draft, S.M.J. and S.-y.P.; and writing—review and editing, S.M.J. and S.-y.P. All authors have read and agreed to the published version of the manuscript.

Funding: This work was supported by a National Research Foundation of Korea (NRF) grant funded by the Korea government (MEST) (No. 2017R1E1A1A01074320).

Informed Consent Statement: Not applicable.

Data Availability Statement: Not applicable.

Conflicts of Interest: The authors declare no conflict of interest. The funders had no role in the design of the study; in the collection, analyses, or interpretation of the data; in the writing of the manuscript, or in the decision to publish the results.

\section{References}

1. Clarke, L.S. Temporal trends in dietary sodium intake among adults aged $\geq 19$ years-United States, 2003-2016. MMWR. Morb. Mortal. Wkly. Rep. 2021, 70, 1478-1482. [CrossRef]

2. He, F.J.; Burnier, M.; MacGregor, G.A. Nutrition in cardiovascular disease: Salt in hypertension and heart failure. Eur. Heart J. 2011, 32, 3073-3080. [CrossRef] [PubMed]

3. Lanaspa, M.A.; Kuwabara, M.; Andres-Hernando, A.; Li, N.; Cicerchi, C.; Jensen, T.; Orlicky, D.J.; Roncal-Jimenez, C.A.; Ishimoto, T.; Nakagawa, T. High salt intake causes leptin resistance and obesity in mice by stimulating endogenous fructose production and metabolism. Proc. Natl. Acad. Sci. USA 2018, 115, 3138-3143. [CrossRef] [PubMed]

4. Peacock, M. Calcium metabolism in health and disease. Clin. J. Am. Soc. Nephrol. 2010, 5, S23-S30. [CrossRef]

5. Blaine, J.; Chonchol, M.; Levi, M. Renal control of calcium, phosphate, and magnesium homeostasis. Clin. J. Am. Soc. Nephrol. 2015, 10, 1257-1272. [CrossRef] [PubMed]

6. Fellner, R.C.; Cook, A.K.; O'Connor, P.M.; Zhang, S.; Pollock, D.M.; Inscho, E.W. High-salt diet blunts renal autoregulation by a reactive oxygen species-dependent mechanism. Am. J. Physiol.-Ren. Physiol. 2014, 307, F33-F40. [CrossRef]

7. Hosohata, K. Biomarkers for chronic kidney disease associated with high salt intake. Int. J. Mol. Sci. 2017, 18, 2080. [CrossRef]

8. Huang, P.; Shen, Z.; Liu, J.; Huang, Y.; Chen, S.; Yu, W.; Wang, S.; Ren, Y.; Li, X.; Tang, C. Hydrogen sulfide inhibits high-salt diet-induced renal oxidative stress and kidney injury in Dahl rats. Oxidative Med. Cell. Longev. 2016, 2016, 2807490. [CrossRef]

9. Wolf, M. Mineral (Mal) adaptation to kidney disease-Young investigator award address: American society of Nephrology kidney week 2014. Clin. J. Am. Soc. Nephrol. 2015, 10, 1875-1885. [CrossRef]

10. Wang, Z.; Sun, Q.; Sun, N.; Liang, M.; Tian, Z. Mitochondrial dysfunction and altered renal metabolism in Dahl salt-sensitive rats. Kidney Blood Press. Res. 2017, 42, 587-597. [CrossRef]

11. Trolliet, M.R.; Rudd, M.A.; Loscalzo, J. Oxidative stress and renal dysfunction in salt-sensitive hypertension. Kidney Blood Press. Res. 2001, 24, 116-123. [CrossRef] [PubMed]

12. McDowell, L.R.; Wilkinson, N.; Madison, R.; Felix, T. Vitamins and minerals functioning as antioxidants with supplementation considerations. In Florida Ruminant Nutrition Symposium; Best Western Gateway Grand: Gainesville, FL, USA, 2007 ; pp. 30-31.

13. Lukaski, H.C. Vitamin and mineral status: Effects on physical performance. Nutrition 2004, 20, 632-644. [CrossRef] [PubMed]

14. Hans, C.P.; Chaudhary, D.P.; Bansal, D.D. Effect of magnesium supplementation on oxidative stress in alloxanic diabetic rats. Magnes. Res. 2003, 16, 13-19.

15. Nani, M.; Zura, S.; Majid, F.; Jaafar, A.; Mahdzir, A.; Musa, M. Potential health benefits of deep sea water: A review. Evid.-Based Complementary Altern. Med. 2016, 2016, 6520475.

16. Jo, S.M.; Nam, J.; Park, G.; Kim, B.G.; Jeong, G.-H.; Hurh, B.S.; Kim, J.Y. Effects of calcium and magnesium-balanced deep sea water on antioxidation in kidney cells. J. Appl. Biol. Chem. 2021, 64, 165-170. [CrossRef]

17. Ba Aqeel, S.H.; Sanchez, A.; Batlle, D. Angiotensinogen as a biomarker of acute kidney injury. Clin. Kidney J. 2017, 10, 759-768. [CrossRef]

18. Gonsalez, S.R.; Ferrão, F.M.; Souza, A.M.d.; Lowe, J.; Morcillo, L.d.S.L. Inappropriate activity of local renin-angiotensinaldosterone system during high salt intake: Impact on the cardio-renal axis. Braz. J. Nephrol. 2018, 40, 170-178. [CrossRef] [PubMed] 
19. Briet, M.; Schiffrin, E.L. Aldosterone: Effects on the kidney and cardiovascular system. Nat. Rev. Nephrol. 2010, 6, $261-273$. [CrossRef] [PubMed]

20. Iglarz, M.; Touyz, R.M.; Viel, E.C.; Amiri, F.; Schiffrin, E.L. Involvement of oxidative stress in the profibrotic action of aldosterone: Interaction with the renin-angiotensin system. Am. J. Hypertens. 2004, 17, 597-603. [CrossRef]

21. Kitiyakara, C.; Chabrashvili, T.; Chen, Y.; Blau, J.; Karber, A.; Aslam, S.; Welch, W.J.; Wilcox, C.S. Salt intake, oxidative stress, and renal expression of NADPH oxidase and superoxide dismutase. J. Am. Soc. Nephrol. 2003, 14, 2775-2782. [CrossRef]

22. Nagase, M.; Fujita, T. Aldosterone and glomerular podocyte injury. Clin. Exp. Nephrol. 2008, 12, 233-242. [CrossRef]

23. Washino, S.; Hosohata, K.; Jin, D.; Takai, S.; Miyagawa, T. Early urinary biomarkers of renal tubular damage by a high-salt intake independent of blood pressure in normotensive rats. Clin. Exp. Pharmacol. Physiol. 2018, 45, 261-268. [CrossRef]

24. Farquhar, M.G.; Saito, A.; Kerjaschki, D.; Orlando, R.A. The Heymann nephritis antigenic complex: Megalin (gp330) and RAP. J. Am. Soc. Nephrol. 1995, 6, 35-47. [CrossRef]

25. Leheste, J.-R.; Rolinski, B.; Vorum, H.; Hilpert, J.; Nykjaer, A.; Jacobsen, C.; Aucouturier, P.; Moskaug, J.Ø.; Otto, A.; Christensen, E.I. Megalin knockout mice as an animal model of low molecular weight proteinuria. Am. J. Pathol. 1999, 155, 1361-1370. [CrossRef]

26. Schreiber, A.; Theilig, F.; Schweda, F.; Höcherl, K. Acute endotoxemia in mice induces downregulation of megalin and cubilin in the kidney. Kidney Int. 2012, 82, 53-59. [CrossRef]

27. Marzolo, M.-P.; Farfán, P. New insights into the roles of megalin/LRP2 and the regulation of its functional expression. Biol. Res. 2011, 44, 89-105. [CrossRef] [PubMed]

28. Gilliland, M.; Zawada, E.T., Jr.; McClung, D.; TerWee, J. Preliminary report: Natriuretic effect of calcium supplementation in hypertensive women over forty. J. Am. Coll. Nutr. 1987, 6, 139-143. [CrossRef]

29. Berthelot, A.; Esposito, J. Effects of dietary magnesium on the development of hypertension in the spontaneously hypertensive rat. J. Am. Coll. Nutr. 1983, 2, 343-353. [CrossRef]

30. Chen, D.; Stegbauer, J.; Sparks, M.A.; Kohan, D.; Griffiths, R.; Herrera, M.; Gurley, S.B.; Coffman, T.M. Impact of angiotensin type 1A receptors in principal cells of the collecting duct on blood pressure and hypertension. Hypertension 2016, 67, 1291-1297. [CrossRef]

31. Guyton, A.C. Blood pressure control—Special role of the kidneys and body fluids. Science 1991, 252, 1813-1816. [CrossRef] [PubMed]

32. Coffman, T.M.; Crowley, S.D. Kidney in hypertension: Guyton redux. Hypertension 2008, 51, 811-816. [CrossRef] [PubMed]

33. Shiose, A.; Kuroda, J.; Tsuruya, K.; Hirai, M.; Hirakata, H.; Naito, S.; Hattori, M.; Sakaki, Y.; Sumimoto, H. A novel superoxideproducing NAD (P) H oxidase in kidney. J. Biol. Chem. 2001, 276, 1417-1423. [CrossRef] [PubMed]

34. Geiszt, M.; Kopp, J.B.; Várnai, P.; Leto, T.L. Identification of renox, an NAD (P) H oxidase in kidney. Proc. Natl. Acad. Sci. USA 2000, 97, 8010-8014. [CrossRef]

35. Bussiere, F.I.; Gueux, E.; Rock, E.; Girardeau, J.-P.; Tridon, A.; Mazur, A.; Rayssiguier, Y. Increased phagocytosis and production of reactive oxygen species by neutrophils during magnesium deficiency in rats and inhibition by high magnesium concentration. $B r$. J. Nutr. 2002, 87, 107-113. [CrossRef]

36. Gao, T.-C.; Cho, J.-Y.; Feng, L.-Y.; Chanmuang, S.; Park, S.-Y.; Ham, K.-S.; Auh, C.-K.; Pai, T.-K. Mineral-rich solar sea salt generates less oxidative stress in rats than mineral-deficient salt. Food Sci. Biotechnol. 2014, 23, 951-956. [CrossRef]

37. Afanas'ev, I.B.; Suslova, T.B.; Cheremisina, Z.P.; Abramova, N.E.; Korkina, L.G. Study of antioxidant properties of metal aspartates. Analyst 1995, 120, 859-862. [CrossRef] [PubMed]

38. Matkovics, B.; Kiss, I.; Kiss, S. The activation by magnesium treatment of anti-oxidants eliminating the oxygen free radicals in Drosophila melanogaster in vivo. Magnes. Res. 1997, 10, 33-38. [PubMed]

39. Zhang, Y.; Davies, L.R.; Martin, S.M.; Bawaney, I.M.; Buettner, G.R.; Kerber, R.E. Magnesium reduces free radical concentration and preserves left ventricular function after direct current shocks. Resuscitation 2003, 56, 199-206. [CrossRef]

40. Das, S.; Choudhuri, D. Dietary calcium regulates the risk renal injury in high fat diet induced obese rats by regulating renal lipid metabolism, oxidative stress and inflammation. Arch. Physiol. Biochem. 2020, 1-11. [CrossRef]

41. Ighodaro, O.; Akinloye, O. First line defence antioxidants-superoxide dismutase (SOD), catalase (CAT) and glutathione peroxidase (GPX): Their fundamental role in the entire antioxidant defence grid. Alex. J. Med. 2018, 54, 287-293. [CrossRef]

42. Lu, S.C. Regulation of glutathione synthesis. Mol. Asp. Med. 2009, 30, 42-59. [CrossRef]

43. Lu, S.C. Glutathione synthesis. Biochim. Et Biophys. Acta (BBA)-Gen. Subj. 2013, 1830, 3143-3153. [CrossRef] [PubMed]

44. Lever, J.M.; Boddu, R.; George, J.F.; Agarwal, A. Heme oxygenase-1 in kidney health and disease. Antioxid. Redox Signal. 2016, 25, 165-183. [CrossRef]

45. Zhang, P.L.; Lun, M.; Schworer, C.M.; Blasick, T.M.; Masker, K.K.; Jones, J.B.; Carey, D.J. Heat shock protein expression is highly sensitive to ischemia-reperfusion injury in rat kidneys. Ann. Clin. Lab. Sci. 2008, 38, 57-64. [PubMed]

46. Boute, N.; Gribouval, O.; Roselli, S.; Benessy, F.; Lee, H.; Fuchshuber, A.; Dahan, K.; Gubler, M.-C.; Niaudet, P.; Antignac, C. NPHS2, encoding the glomerular protein podocin, is mutated in autosomal recessive steroid-resistant nephrotic syndrome. Nat. Genet. 2000, 24, 349-354. [CrossRef] [PubMed]

47. Roselli, S.; Gribouval, O.; Boute, N.; Sich, M.; Benessy, F.; Attié, T.; Gubler, M.-C.; Antignac, C. Podocin localizes in the kidney to the slit diaphragm area. Am. J. Pathol. 2002, 160, 131-139. [CrossRef] 
48. Liu, W.; Baker, S.S.; Baker, R.D.; Nowak, N.J.; Zhu, L. Upregulation of hemoglobin expression by oxidative stress in hepatocytes and its implication in nonalcoholic steatohepatitis. PLOS ONE 2011, 6, e24363. [CrossRef] [PubMed]

49. Dai, Q.; Shu, X.-O.; Deng, X.; Xiang, Y.-B.; Li, H.; Yang, G.; Shrubsole, M.J.; Ji, B.; Cai, H.; Chow, W.-H. Modifying effect of calcium/magnesium intake ratio and mortality: A population-based cohort study. BMJ Open 2013, 3, e002111. [CrossRef]

50. Hyun, Y.J.; Kim, J.G.; Kim, M.J.; Jung, S.K.; Kim, J.Y. Mineral-rich Jeju lava sea water suppresses lipid accumulation in 3T3-L1 adipocytes and ameliorates high-fat diet-induced obesity in C57BL/6 J mice. Food Sci. Biotechnol. 2021, 30, 299-304. [CrossRef]

51. Ohkawa, H.; Ohishi, N.; Yagi, K. Assay for lipid peroxides in animal tissues by thiobarbituric acid reaction. Anal. Biochem. 1979, 95, 351-358. [CrossRef] 